\title{
Combined Treatment with 2-Deoxy-D-Glucose and Doxorubicin Enhances the in Vitro Efficiency of Breast Cancer Radiotherapy
}

\author{
Jalil Pirayesh Islamian ${ }^{1 *}$, Fahimeh Aghaee $^{1}$, Alireza Farajollahi ${ }^{1}$, Behzad \\ Baradaran $^{2}$, Mona Fazel ${ }^{1}$
}

\begin{abstract}
Doxorubicin (DOX) was introduced as an effective chemotherapeutic for a wide range of cancers but with some severe side effects especially on myocardia. 2-Deoxy-D-glucose (2DG) enhances the damage caused by chemotherapeutics and ionizing radiation (IR) selectively in cancer cells. We have studied the effects of $1 \mu \mathrm{M}$ DOX and $500 \mu \mathrm{M} 2 \mathrm{DG}$ on radiation induced cell death, apoptosis and also on the expression levels of p53 and PTEN genes in T47D and SKBR3 breast cancer cells irradiated with 100, 150 and 200 cGy $x$-rays. DOX and 2DG treatments resulted in altered radiation-induced expression levels of p53 and PTEN genes in T47D as well as SKBR3 cells. In addition, the combination along with IR decreased the viability of both cell lines. The radiobiological parameter (D0) of T47D cells treated with 2DG/DOX and IR was 140 cGy compared to 160 cGy obtained with IR alone. The same parameters for SKBR3 cell lines were calculated as 120 and 140 cGy, respectively. The sensitivity enhancement ratios (SERs) for the combined chemo-radiotherapy on T47D and SKBR3 cell lines were 1.14 and 1.16, respectively. According to the obtained results, the combination treatment may use as an effective targeted treatment of breast cancer either by reducing the single modality treatment side effects.
\end{abstract}

Keywords: 2DG - breast cancer - cell line - combined modality therapy - Doxorubicin

Asian Pac J Cancer Prev, 16 (18), 8431-8438

\section{Introduction}

There are undeniable evidences on diversity of expression levels of oncogenes and suppressor genes in a cancer. Therefore, there wasn't seen a constant response in a cancer for a therapy modality. Compilation of the mutation data were revealed two prevalent gene mutation patterns among the breast cancer cell lines (SKBR3 and T47D). The first pattern involved frequent mutations among the cell lines in genes from the same tumor suppressor pathway. These were included the p53 pathway in $90 \%$ of the cell lines (p53), the RB pathway in $64 \%$ (p16) and the PI3K pathway in 56\% phosphatase and tensin homologue (PTEN) (Hollestelle et al., 2007).

Gene protein expression level studies have demonstrated that, in breast cancer, there is an overexpression of PTEN in SKBR3 breast cancer cells, as with the estrogen receptor negative cancer cells, containing the wild-type PTEN and normal expression of p53. Whereas, there is an overexpression of p53 in T47D breast cancer cells, as estrogen receptor positive cancer cells, containing wildtype p53 and normal expression of PTEN. In addition to inducing genes that drive apoptosis, $\mathrm{p} 53$ can also activate the expression of genes that inhibits survival signaling (such as PTEN) or delay inhibitors of apoptosis (such as BIRC5) (Meek, 2004; Nakamura, 2004; Lu et al., 2005).
Also, PTEN, a dual specificity PIP3 phosphatase that antagonizes AKT signaling, is capable of blocking MDM2 nuclear translocations, thus preventing the negative effects of growth factors on p53 activity. PTEN may also be viewed as a tumor suppressor.

In the other hand, the induction of PTEN is essential for p53-mediated apoptosis so underscoring the importance of the AKT survival, signaled in determining the final outcomes of the p53 response. Consequently, p53 increases PTEN and PTEN decreases AKT activity. Breast tumors with a high levels of p53 expression are more frequently ER-negative and also with a higher proliferation rate and a poorer prognosis. The ERpositives, due to lack of p53 function, often respond poorly to radiation and chemotherapy. On the other hand, one of the major challenging problems in oncology, including chemotherapy, is the correlation of experimental and clinical data.

The chemo-radiotherapy can have two strategic potentials. One potential is to eradicate tumor cells outside of the irradiated field. This is defined as adjuvant use of the chemotherapeutics. So far, it does not assume any biological interaction occurring between the chemotherapeutics and ionizing radiation (IR), regarding to tumor cell killing. The second potential is to enhance the local control of radiotherapy. The clinician calls 
this sensitization but, in a truly biological sense, this may not be occurring. Doxorubicin (Adriamycin), as a chemotherapeutics, has revealed the importance of cell cycle characteristics, tumor-cell density, and induced resistance as critical factors upon the interaction efficiency of doxorubicin and IR (Carter, 1979; Aghaee et al., 2013). Doxorubicin has been used to treat a wide range of cancers as an effective cancer therapy for over 30 years (Tan et al., 2009), also in treatment of breast cancer (O'Shaughnessy, 2003; Tan et al., 2009). Monotherapy with doxorubicin has shown a good response rate of 10-50\% (Moulder and Hortobagyi, 2008), and doxorubicin-containing combination therapies were usually resulted in a better survival rate (Bergh et al., 2001; O'Shaughnessy, 2003; Gonzalez-Angulo et al., 2007). Doxorubicin forms a stable complex with DNA and topoisomerase II $\alpha$, resulting in inhabitation of normal function of the enzyme in DNA strand break repairing hence induces single and double strand breaks in DNA (Tewey et al., 1984). Therefore, the increased expression level of $\mathrm{p} 53$ protein after doxorubicin treatment is a response to doxorubicin induced DNA damage (Kaabinejadian and Azizi, 2008). There are many chronic side effects that limit the curative dose of doxorubicin that can be executed; the most detrimental side effect is the cardiomyopathy that may lead to irreversible congestive heart failures (Kerr, 1994). In fact, the cardiac toxicity of doxorubicin may be related to the intracellular generations of reactive oxygen metabolites following the treatment (Carter, 1978). On the other hand, the ubiquitous expression of topoisomerases contributes to the nonselective targeting of doxorubicin, and is a major reason for the toxicity (Bergh et al., 2001). The toxicity may be reduced if doxorubicin is used in conjunction with the tumor-specific treatment modalities for compensation.

Meanwhile, studies on the metabolism pathways of cancer cells have demonstrated that accelerated glucose uptake for anaerobic glycolysis (Warburg effect)( Mohanti et al., 1996; Pelicano et al., 2006; Gupta et al., 2009; Sinthupibulyakit et al., 2009; Mustafa et al., 2015), and the loss of regulation between glycolyticmetabolism and respiration(Simons et al., 2007), are the major metabolic changes found in malignant cells. In general, cancer cells have increased rates of glycolysis as well as pentose phosphate cycle activity, and slightly reduced rates of respiration (Simons et al., 2007; Aykin-Burns et al., 2009). Enhanced glucose uptake and glycolysis in tumors are elevated due to multiple reasons including oncogenic transformation-linked alterations in gene expression, mitochondrial mutations and hypoxia in the case of solid tumors that result in enhanced the levels and the activities of glucose transporter and glycolytic enzymes (Pelicano et al., 2006; Zhang and Aft, 2009). This metabolic feature has led to the hypothesis that inhibition of glycolysis may severely abolish ATP generation in cancer cells and thus may preferentially kill the malignant cells (Pelicano et al., 2006). Several studies have shown that glucose deprivation can induce cytotoxicity in transformed human cell types via metabolic oxidative stress (Ahmad et al., 2010). Glucose analogs have been found to profoundly inhibit glucose metabolism in cancer cells in vitro and in vivo (Gupta et al., 2009; Sinthupibulyakit et al., 2009;
Zhang and Aft, 2009; Ahmad et al., 2010; Mustafa et al., 2015). Of the many glucose analogs which have been investigated, 2-Deoxy-D-Glucose (2DG) has been proven effective in the inhibition of tumor metabolism and ATP production (Gupta et al., 2009; Ahmad et al., 2010; Mustafa et al., 2015; Wang et al., 2015). Therefore, 2DG has suggested as an adjuvant of radiation therapy and chemotherapy both in vitro and in vivo (Gupta et al., 2009).

2DG enhances the damage caused by chemotherapeutic and ionizing radiation, selectively in cancer cells (Dwarakanath, 2009; Gupta et al., 2009; Zhang and Aft, 2009; Aghaee et al., 2012), through the mechanisms such as inhibiting the DNA repair processes and recovering from the potentially lethal damage (Gupta et al., 2009; Zhang and Aft, 2009). 2DG induced radiosensitization has also been suggested to be due to disruption of thiol metabolism resulting in oxidative stress-related cell death in the form of apoptosis (Dwarakanath, 2009). However, in the attempts to finding out the role of 2DG in radiation therapy, only one clinical trial study on human cerebral gliomas has demonstrated that 2DG improves the efficacy of radiotherapy (Mohanti et al., 1996; Zhang and Aft, 2009; Ghilotti et al., 2010). Analyzing of the radiomodifying effects of $2 \mathrm{DG}$, observed in several tumor cell lines, revealed that the administration time of 2DG with respect to irradiation plays an important role in determining the effects (Dwarkanath et al., 2001; Dwarakanath, 2009; Gupta et al., 2009). It was shown that $2 \mathrm{DG}$ results in cessation of cell growth, in a dose dependent manner, and reduces adhesion and migration of breast cancer cells when combined with doxorubicin or L-Buthionine Sulfoximine (Mustafa et al., 2015). Also it was suggested that evaluation of glucose usage, lactate production, and energy status could be useful for predicting the responses of tumors to the combined treatment of radiation and 2DG (Dwarkanath et al., 2001).

Combination of DOX and 2DG therapy may enhance the effectiveness of cancer radiotherapy and reduce the related side effects from the single treatment modalities.

\section{Materials and Methods}

\section{Cell culture}

The human breast cancer cell lines, SKBR3 and T47D (purchased from Institute Pasteur, National Cell Bank, Iran), were grown in RPMI-1640 media supplemented with $10 \%$ heat-inactivated $\left(50^{\circ} \mathrm{C}, 30 \mathrm{~min}\right)$ fetal bovine serum, penicillin $\left(100 \mathrm{U} \mathrm{mL}^{-1}\right)$, streptomycin $(100 \mu \mathrm{g}$ $\left.\mathrm{mL}^{-1}\right)$, and amphotericin $\mathrm{B}\left(0.25 \mu \mathrm{g} \mathrm{mL}^{-1}\right)$ at $5 \% \mathrm{CO}_{2}$ in a $95 \%$ humidified $37^{\circ} \mathrm{C}$ incubator.

\section{Chemodrugs and radiation treatment}

Stock solutions of $1 \mathrm{M}$ doxorubicin (Sobhan Chemotherapeutics Co., Tehran, Iran) were dissolved in PBS and diluted in the culture medium to a final concentration of $1 \mu \mathrm{M}$ doxorubicin and the cells treated for 24 hours prior to irradiation and subsequently incubated $(11,30)$. Also a prepared stock solution of 2DG(Sigma Aldrich, Germany), $\geq 98 \%$ GC, diluted in the culture medium to a final concentration of $500 \mu \mathrm{M}$ and the 
cells treated for $4 \mathrm{~h}$ prior to irradiation and subsequently incubated (Zhang and Aft, 2009). A 9MV linear accelerator $\mathrm{X}$-ray machine (Linac Neptune, Warsaw, Poland) was used to irradiate the cells with doses of 100, 150, $200 \mathrm{cGy}$.

\section{MTT assay for cell viability}

T47D and SKBR3 cells (7000 cells/well) were incubated in the 96-well plates, each containing $200 \mu \mathrm{l}$ supplemented cell culture media, for 24 hours at $37^{\circ} \mathrm{C}$ and $5 \% \mathrm{CO}_{2}$. The cells were divided in four groups in triplicates: blank, chemodrugs, radiation, chemo-radio combined treated. In chemodrugs treated groups, the cells treated with a final concentration of $1 \mu \mathrm{M}$ doxorubicin for 24 hours and/or $500 \mu \mathrm{M} 2 \mathrm{DG}$ for 4 hours. The rate of cellular proliferation was measured after 24 hours by MTT assay method. Briefly, $10 \mu \mathrm{l}$ of $5 \mathrm{mg} / \mathrm{ml}$ MTT (3-(4, 5-dimetylthiazol-2-yl)-2, 5-diphenyltrazolium bromide) (Roche Diagnostics GmbH, Mannheim, Germany) was added to each well. Then the cells were incubated for 4 hours, at $37^{\circ} \mathrm{C}$ and $5 \% \mathrm{CO}_{2}$, and $200 \mu \mathrm{l}$ of DMSO was added to each well, after discarding the media, to solubilize the colored formazan product and then $25 \mu 1$ Sorenson buffer was added to each well as solubilizer buffer. Finally, absorbance was read using an ELISA plate reader (BioTeck, Bad Friedrichshall, Germany) at $570 \mathrm{~nm}$ wavelength. All the obtained data were analyzed relatively to the untreated cells and then normalized.

\section{Clonogenic survival assay}

The clonogenic survival assay was used to investigate the radiosensitivity of T47D and SKBR3 cells exposed with the 2DG and/or doxorubicin. Briefly, the Cells (2000 cells/well) were plated at in 6-well plates, allowed to attach in 24 hours and subsequently exposed to doxorubicin and 2DG for 24 and 4 hours, respectively, followed by the radiation. Then, the wells were washed and the culture renewed and the cells incubated for 14 days at $37^{\circ} \mathrm{C}$ in a humidified incubator. Finally, the produced colonies were counted after fixing with a mixture of methanol-acetic acid (3:1) and staining in a $10 \%$ giemsa solution. The survival curves were plotted using the GraphPad Prism 6(GraphPad Software, Inc., San Diego, CA, USA).

\section{Cell death detection}

The induced apoptosis and necrosis of T47D \& SKBR3 cells (7000 cells), following the mentioned treatments were measured using a Cell Death Detection ELISA ${ }^{\text {PLUS }}$ kit (Roche Diagnostics GmbH, Mannheim, Germany). The procedure was performed according to the manufacturer's protocol. Briefly, the supernatants and lysate of the cells were prepared and incubated in the microtiter plates coated with the anti-histone antibodies. The colored reactions were analyzed using a ELISA plate reader (BioTeck, Bad Friedrichshall, Germany) at $405 \mathrm{~nm}$ wavelength.

\section{RNA extraction}

The total RNA of the cells was extracted using RNXPlus reagent (Cinagen Co., Tehran, Iran.). Briefly, $10^{6}$ cells were treated with $1 \mathrm{ml}$ of RNX solution and incubated at room temperature for 5 minutes. After adding 200 $\mu l$ chloroform, the cell suspensions were centrifuged in
$12000 \mathrm{RPM}$ at $4^{\circ} \mathrm{C}$ for 15 minutes. Then, the upper phase was transferred to a new tube containing isopropanol. After high speed centrifugation at $4^{\circ} \mathrm{C}$ for 15 minutes, the supernatant was discarded and the RNA-pellet was washed out with $75 \%$ ethanol. Finally, the RNA-pellet was dissolved in DEPC treated water, after drying, and concentration of the purified RNA was determined by optical density measurement at 260 and $280 \mathrm{~nm}$ wavelengths.

\section{cDNA synthesis}

Reverse transcriptase reaction was performed using RevertAid $^{\mathrm{TM}}$ First Strand cDNA synthesis kit (MBI, Fermentas, Lithuania). Briefly, the RNAs were treated with DNase I (Invitrogen, Carlsbad, CA, USA) before cDNA synthesis to avoid DNA contamination. cDNA was retrotranscripted in $20 \mu 1$ reaction solution containing 5 $\mu \mathrm{g}$ total RNA, reaction buffer, RNase inhibitor (20 U), dNTP mix (20 nM), random hexamer primer, oligo (dt)18 primer, and $200 \mathrm{U}$ M-MuLV reverse transcriptase. Reverse transcription procedure was performed at $42^{\circ} \mathrm{C}$ for 60 minutes and terminated by heating at $70^{\circ} \mathrm{C}$ for 5 minutes.

\section{Quantitative RT-PCR}

The specific primer sequences designed for p53 and PTEN and $\beta$-actin ribosomal RNA using free online Primer BLAST software (fast prim 6) and the gene confirmation was done with GeneDetect ${ }^{\circledR}$ oligonucleotide gene probes (Oligo 3) as following:

PTEN primers: 5'- CAGAbGCCAAGCGG CGGCAGA-3 (forward primer) and 5'-AGAAGCTGCTGGTGGCGGGG-3' (reverse primer), p53 primers: 5'- TGGGCGTGAGCGCTTCGAGA-3' (forward primer) and 5'- GGTGGCTGG AGTGAGCCCTGC-3' (reverse primer), $\beta$-actin primers: 5'- TCCCTGGAGAAGAGCTACG-3' (forward primer) and 5'- GTAGTTTCGTGGATGCCACA-3' (reverse primer).

$\beta$-actin was used as an internal control and the relative gene expression was measured by the $2^{-\Delta \mathrm{Ct}}$ formula: Expression $_{\text {Target Gene } / \beta \text {-actin Gen }}=(1+\mathrm{E})^{-\mathrm{Ct}}$ Target Gene $/(1+\mathrm{E})^{-\mathrm{Ct}}$ $\beta$-actin Gen. All Real-time PCR reactions were executed in 72-well reaction tubes containing 2x SYBER GREEN PCR master mix reagent (ABI, Vernon, CA, USA), 190nM primer and $1 \mu \mathrm{g}$ cDNA in the $20 \mu 1$ reaction volume. Quantitative RT PCR was performed using CorbettGene 6000 thermo cycler (Corbett Life Science, Sydney, Australia). The thermal cycle conditions were included one thermal cycle of $95^{\circ} \mathrm{C}$ for 5 minutes followed by 42 cycles of $95^{\circ} \mathrm{C}$ for $20 \mathrm{~s}$ (denaturation) and $60^{\circ} \mathrm{C}$ for $20 \mathrm{~s}$ (annealing) and $72^{\circ} \mathrm{C}$ for 20 s (extension). Accuracy of the reaction was confirmed by the melting curve analysis with Corbett Rotor-Gene 6000 software (Corbett Life Science, Sydney, Australia).

\section{Statistics}

MTT assay data were processed as medians. Nonparametric Mann-Whitney test was used to compare the frequency of death in the groups. Also the Spearman's correlation was used to find statistically significant correlations. The expression levels of the target genes 
Jalil Pirayesh Islamian et al

were obtained by the Corbett Rotor-Gene 6000 software and were expressed as $\mathrm{Ct}$ (cycle threshold), $\Delta \mathrm{Ct}$ (the subtraction of target and housekeeping genes). Amplification efficiency of each cytokine was being evaluated concerning 18s RNA expression as internal control and analyzing $\Delta \mathrm{Ct}$ variations of the template DNA dilutions. Graphs were plotted with the Graphpad Prism 6 (2012 GraphPad Software, Inc., San Diego, CA, USA). Normal distribution of the data were determined using P-P plots and statistically analyzed using statistical SPSS software, version 21 .

\section{Results}

Cytotoxic effects of combined doxorubicin and 2DG treatments followed by irradiation on breast cancer cell lines

Figure $1 \mathrm{~A}$ and $1 \mathrm{~B}$ show the results on cell viability analysis of T47D and SKBR3 breast cancer cells, incubated with $1 \mu \mathrm{M}$ doxorubicin and $500 \mu \mathrm{M} 2 \mathrm{DG}$ for 24 and $4 \mathrm{~h}$, respectively, followed by irradiation with the doses of 100,150, and $200 \mathrm{cGy}$. The reduced cell viabilities
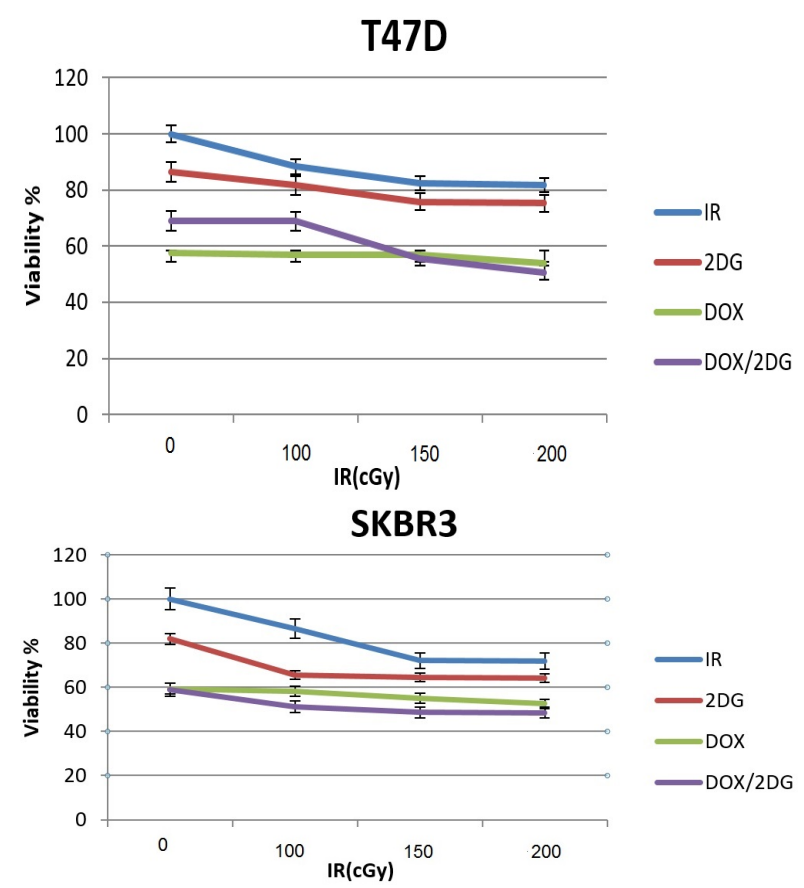

Figure 1. Viability of T47D. (A) and SKBR3; (B) cell lines following treatment with $1 \mu \mathrm{M}$ doxorubicin, $500 \mu \mathrm{M}$ 2-Deoxy-D-Glucose, and 100,150, 200 cGy irradiation. $\mathrm{IR}=$ Irradiation, DOX=Doxorubicin, $2 \mathrm{DG}=2$-Deoxy-DGlucose were statistically significant for IR/2DG/DOX treatment in T47D $(\mathrm{p}<0.02)$ and SKBR3 $(\mathrm{p}<0.05)$ cells.

Effects of combined doxorubicin and $2 D G$ treatments followed by irradiation on induction of apoptosis

The results on the treatment induced apoptosis and
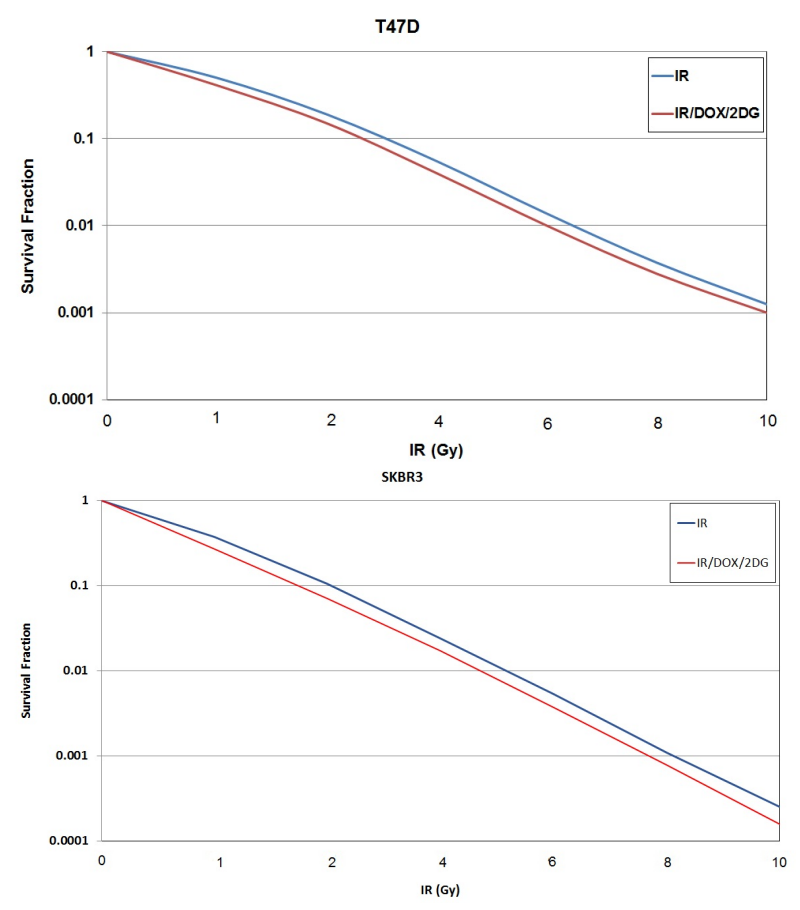

Figure 2. Clonogenic survival curves of T47D. (A) and SKBR3; (B) breast cancer cells from combined treatment with $1 \mu \mathrm{M}$ Doxorubicin,500 $\mu \mathrm{M}$ 2-Deoxy-D-Glucose followed by irradiation (IR/DOX/2DG), and radiation alone(IR)

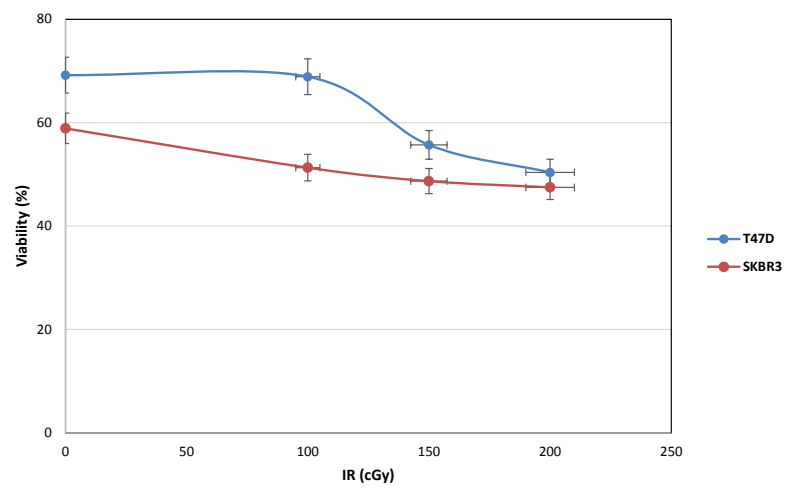

Figure 3. Viability of T47D and SKBR3 Breast Cancer Cell Lines Treated with $1 \mu \mathrm{M}$ Doxorubicin for $24 \mathrm{~h}$ and $500 \mu \mathrm{M}$ 2DG for $4 \mathrm{~h}$ Followed by Irradiation

Table 1. Results of ELISA Analysis on Assessment of Apoptosis and Necrosis in T47D and SKBR3 Breast Cancer Cell Lines Induced by 150Gy Irradiation, $1 \mu \mathrm{M}$ Doxorubicin and/or $500 \mu \mathrm{M}$ 2-Deoxy-D-Glucose

\begin{tabular}{|c|c|c|c|c|c|c|c|c|}
\hline \multirow[t]{2}{*}{ Treat } & \multicolumn{2}{|c|}{ Necrosis OD* } & \multicolumn{2}{|c|}{ Apoptosis OD } & \multicolumn{2}{|c|}{ Necrosis $\%$} & \multicolumn{2}{|c|}{ Apoptosis $\%$} \\
\hline & $\mathrm{T} 47 \mathrm{D}$ & SKBR3 & T47D & SKBR3 & $\mathrm{T} 47 \mathrm{D}$ & SKBR3 & $\mathrm{T} 47 \mathrm{D}$ & SKBR3 \\
\hline IR** & 0.024 & 0.09 & 0.208 & 0.378 & 10.3 & 19.2 & 89.6 & 80.7 \\
\hline DOX & 0.036 & 0.043 & 0.058 & 0.33 & 38.29 & 11.52 & 61.7 & 88.4 \\
\hline $2 \mathrm{DG}$ & 0.001 & 0.062 & 0.038 & 0.21 & 2.5 & 22.7 & 92.1 & 77.2 \\
\hline $\mathrm{DOX} / 2 \mathrm{DG} / \mathrm{IR}$ & 0.01 & 0.26 & 0.13 & 0.65 & 7.1 & 28.5 & 92.8 & 71.4 \\
\hline
\end{tabular}

*OD: Optical Density; ** IR: Irradiation 
Table 2. Results for mRNA Expression levels of p53 and PTEN in T47D and SKBR3 Breast Cancer Cell Lines Following Doxorubicin and/or 2-Deoxy-D-Glucose Treatment Followed by Irradiation

\begin{tabular}{|c|c|c|c|c|c|c|c|c|c|}
\hline \multicolumn{10}{|c|}{ Treatment } \\
\hline & \multicolumn{3}{|c|}{ DOX/2DG/IR } & \multicolumn{3}{|c|}{ 2DG/IR } & \multicolumn{3}{|c|}{ DOX/IR } \\
\hline \multicolumn{10}{|l|}{ Cell line } \\
\hline Gene\# & 200 & 150 & 100 & 200 & 150 & 100 & 200 & 150 & 100 \\
\hline \multicolumn{10}{|l|}{ T47D } \\
\hline P53 & 0.007 & 0.011 & 0.134 & 2678.211 & 319.62 & 465.928 & 10.271 & 0.007 & 4.812 \\
\hline PTEN & 1.078 & 0.34 & 0.155 & 23.96 & 10.628 & 19.521 & 3993.208 & 410.431 & 1959.442 \\
\hline \multicolumn{10}{|l|}{ SKBR3 } \\
\hline P53 & 0.134 & 0.595 & 0.74 & 5.405 & 3.789 & 0.087 & 0.491 & 0.878 & 0.195 \\
\hline \multirow[t]{2}{*}{ PTEN } & 0.205 & 0.509 & 0.607 & 1.812 & 0.544 & 0.084 & 8.541 & 8.032 & 5.117 \\
\hline & $\mathrm{DOX} / 2 \mathrm{DG}$ & $2 \mathrm{DG} \dagger$ & DOX*** & & $\mathrm{IR}^{* *}$ & & & & \\
\hline \multicolumn{10}{|l|}{ Cell line } \\
\hline Gene\# & 0 & 0 & 0 & 200 & 150 & $100 *$ & & & \\
\hline \multicolumn{10}{|l|}{$\mathrm{T} 47 \mathrm{D}$} \\
\hline P53 & 0.009 & 543.897 & 1 & 36.346 & 0.003 & $62.348+\dagger$ & & & \\
\hline PTEN & 0.224 & 5.669 & 0.264 & 6.196 & 0.076 & 54.106 & & & \\
\hline \multicolumn{10}{|l|}{ SKBR3 } \\
\hline P53 & 1.178 & 1.341 & 1.162 & 5.188 & 4.619 & 2.883 & & & \\
\hline PTEN & 0.006 & 3.815 & 4.084 & 5.866 & 22.378 & 17.5 & & & \\
\hline
\end{tabular}

necrosis, obtained from ELISA analysis, were shown in Table 1 for SKBR3 and T47D breast cell lines.

Effects of combined doxorubicin and 2DG treatments followed by irradiation on the mRNA levels of p53 and PTEN

The results of the combined doxorubicin and $2 \mathrm{DG}$ treatments followed by irradiation on the expression levels of p53 and PTEN mRNAs in T47D and SKBR3 cell lines are presented in table2. The mRNA expression was analyzed by RT-PCR and the relative intensity of each bands was measured and normalized with $\beta$-actin.

Effects of combined doxorubicin and $2 D G$ treatments followed by irradiation on the cells clonogenic survival

The results on clonogenic survival of T47D and SKBR3 breast cancer cells following the combined doxorubicin and 2DG treatment followed by irradiation are shown in figure $2 \mathrm{~A}$ and $2 \mathrm{~B}$, respectively. The radiobiological parameter (D0) of T47D cells, treated with radiation and 2DG/DOX, was calculated 140 cGy compared to the irradiation alone, $160 \mathrm{cGy}$. The measures for SKBR3 cell lines were obtained 120 and 140 cGy, respectively. Also, Sensitive Enhancement Ratio obtained from the relation; $(\mathrm{SER})=\mathrm{D} 0$ (D0 of irradiation group) $/(\mathrm{D} 0$ of irradiation+2DG/DOX group), were determined 1.14 and 1.16 for T47D and SKBR3 cell lines, respectively. Meanwhile, the curve was also steepened for the combined treatments (Figure 2), suggested a reduced resistance of the cells to the radiation damage by $2 \mathrm{DG}$ and DOX cotreatment.

\section{Discussion}

In the present study, effects of a low dose of doxorubicin and also 2 - deoxy - D - glucose on cell viability, expression levels of p53 and PTEN genes, and radiation responses have been investigated in the malignant human breast cell lines (T47D, SKBR3). An induced killing effect of $1 \mu \mathrm{M}$ doxorubicin and $500 \mu \mathrm{M}$ 2DG on the breast cancer cells was studied following 24 and 4 hours treatment, respectively (Figure 3). It was found that the chemo-radiotherapy had a higher killing effect than doxorubicin/2DG alone(Table 2). Doxorubicin chemotherapyis a useful treatment in a wide range of cancers (Hortobagyi, 1997; Chabner et al., 2001). Doxorubicin, as an intercalating agent and wedges between the DNA bases, blocks DNA synthesis and transcription as well as inhibits the activity of topoisomerase type II (Tewey et al., 1984). Thus leads to breaks in the genomic DNA. Both of the mechanisms result in DNA disruption that ultimately can lead to the death of the cells. Common side effects include: "Radiation recall" (can bring back skin damage from previous radiation therapy), decreased blood cell counts, increased risk of infection and bleeding, loss of appetite, stomatitis, alopecia (hair loss), Nausea and vomiting, mouth sores, birth defects, liver toxicity, and acute arrhythmia. Cardiac toxicity becomes relevant at high doses. If present, the cardiomyopathy may lead to irreversible congestive heart failures (Kerr et al., 1994). The low dose treatment may diminish the effects but with a decreased curability. In our study, presence of $1 \mu \mathrm{M}$ doxorubicin for 24 hours followed by irradiation, with the doses of 100, 150 and $200 \mathrm{cGy}$, was showed a higher efficiency than the irradiation alone(Figure 1). Meanwhile, the combined chemo-radiotherapy at 100 cGy showed increased radiosensitivity in SKBR3 cell line, compared to T47D cell line and confirmed the results of Kaabinejadian et al (Kaabinejadian and Azizi, 2008). SKBR3 cell lines became more sensitive than T47D by increasing the doses of radiation. It seems that the high doses of radiation have significant effect on rapidly growing cells, SKBR3, 
compared to T47D. In ER-negative cell line (SKBR3) with an upregulation of P53, treatment with Doxorubicin alone also caused a high expression levels of p53 mRNA. Statistically significant correlations were observed between T47D and SKBR3 cell lines in doxorubicin and radiation treatment groups $(\mathrm{p}<0.05)$. Our study showed that $150 \mathrm{cGy}$ radiation resulted to a limited increase of PTEN expression and decrease in p53 expression in T47D cells compared with 100 and 200 cGy radiation (Table 2). A number of studies on response of the cells to ionizing radiation have also shown different respond for similar conditions, and also for the genes expression ( $\mathrm{Ju}$ et al., 2007; Zhuang et al., 2009; Sasaki et al., 2012). This study demonstrate the ability of doxorubicin at low dose, $1 \mu \mathrm{M}$, as an effective treatment of breast cancer when used alone and also combined with ionizing radiation. Adding a third treatment, 2DG in a low dose, to the combined showed an increased the cell killing effect by an additive damage approach.

2DG is phosphorylated by hexokinase to 2-deoxy-Dglucose-6-phosphate (2DG-6-P) inside the cell. 2DG-6-P is not a substrate for glucose-6-phosphate dehydrogenase or phosphohexoisomerase. Therefore, once formed, 2DG6-P is not further metabolized, and, therefore, the output from glycolysis (ATP) and the pentose phosphate pathway gets reduced, and 2DG-6-P accumulates in the cell until dephosphorylated by phosphorylase (Maher et al., 2004; Pelicano et al., 2006; Dwarakanath, 2009; Aghaee et al., 2012; Mustafa et al., 2015). 2DG treatment resulted in intracellular ATP depletion as a consequence of glycolysis inhibition. 2DG treatment was also shown to increase metabolic oxidative stress (Lee et al., 1998; Butt et al., 2000; Spitz et al., 2000; Lin et al., 2003). Such a stress can generate reactive oxygen species, which are capable of inducing Akt phosphorylation (Streffer et al., 1986; Esposito et al., 2003). Our study showed that $500 \mu \mathrm{M}$ 2DG treatment 4 hours prior to irradiation augmented the effects of radiation with relation to the treatment dose per fraction in cancer radiotherapy, higher than 2DG alone, and successfully reduced the cell viability. In present study, combined chemo-radiotherapy showed an increased radiosensitivity in SKBR3 and T47D cell lines (Figure 1), and confirmed results of previous studies (Dwarkanath et al., 2001; Lin et al., 2003; Dwarakanath, 2009; Gupta et al., 2009). Also SKBR3 cell lines were found to be more sensitive than T47D by increasing the doses of radiation for apoptosis induction following the treatment (Table 1). It seems that the combined therapy have significant effect on rapidly growing cells, SKBR3, compared to T47D (Figure 2). In ER cell line (SKBR3) treatment with 2DG alone also caused the high expression of p53 mRNA. The results on ER+ cell line (T47D), showed that the expression of $\mathrm{p} 53$ became higher after combined treatment in compared with control.

Our study showed that $150 \mathrm{cGy}$ of radiation resulted to a significant decrease of PTEN and p53 expression in T47D cells but a limited increased in SKBR3 cells compared to the $100 \mathrm{cGy}$ treatmetns (Table 2). A number of studies on the respond of cells to ionizing radiation have also shown different respond for similar conditions, and also for the genes expression (Ju, et al., 2007; Zhuang et al., 2009; Sasaki et al., 2012). Therefore, it seems to need some extended studies.

These experiments indicate that 2DG inhibits breast cancer cell growth which may be due to either growth arrest or cell death and that competition for essential sites of inhibition is in favor of 2DG. A study have showed that among breast cancer cell lines tested, SKBR3 was the most sensitive to the growth inhibitory effects of 2DG (Mustafa et al., 2015). In our study, the combination of 2DG and radiation, at different doses, caused cell killing and was significantly different from either treatment alone in both cell lines (Figure 1B). These findings support previous studies, showing 2DG-induced growth inhibition and cytotoxicity on MDA-MB231 cells (Andringa et al., 2006), and on FaDu cells (Simons et al., 2007). Furthermore, our results were consistent with a previous study by Singh et al (Singh et al., 1999), showing that the growth rate of rapidly dividing DU145 prostate cancer cells depend on high levels of glucose consumption, whereas the growth rate of relatively slow-growing LNCaP cells are much less dependent on glucose (Singh et al., 1999). They found a direct correlation between glycolytic capacity and degree of growth inhibition in response to glucose deprivation for the cell lines.

Radiosensitization induced by 2DG has also been suggested to be due to disruption of thiol metabolism resulting in oxidative stress-related cell death in the form of apoptosis (Lin et al., 2003), that could be reduced by the addition of $\mathrm{N}$-acetyl cysteine (Coleman et al., 2008), and enhanced by inhibiting glutamate cysteine ligase activity (Andringa et al., 2006). Alterations in expression levels of many genes involved in damage response pathways including DNA repair and apoptosis, transcriptional regulators, cell signaling, besides energy metabolism have been reported that could significantly influence on the radiosensitization of tumor cells (Dwarakanath and Jain, 1987). A robust UPR was also induced by 2DG that contributes to the radiosensitization (Heminger et al., 2006). The 2DG-induced enhancement of radiation damage has been found to be directly proportional to the glucose usage, presence of hypoxia, and doses of 2DG and radiation (Dwarkanath et al., 2001; Khaitan et al., 2006), as our finding.

A great degree of heterogeneity in the 2DG-induced modifications in radiation responses has been observed among the various human tumor cell lines (Dwarkanath et al., 2001), that does not correlate well with the extent of decrease in the energy status (ATP levels), suggesting thereby that other disturbances caused by 2DG also play important roles in the modifications of cellular responses to damage caused by radiation and chemotherapeutics. These include (but not restricted to) the levels of glucose transporters (glut1 and glut3), prosurvival and prodeath regulators, namely, c-myc, ras, p53, p21, Bcl 2/Bax ratio, NF-kB, etc., imbalances in the oxidative stress, alterations in UPR responses, and upregulation of VEGF induced by $2 \mathrm{DG}$. Analysis of the radiomodifying effects of $2 \mathrm{DG}$ observed in several tumor cell lines reveal that the time of administration of 2DG with respect to irradiation plays an important role in determining the effects. Sensitization is generally found to be higher when 2DG added either just 
before $(<5$ minutes $)$ or immediately after $(<5$ minutes $)$ irradiation is present in the incubating medium for $2-4$ hours. Since majority of the damage response pathways (particularly DNA repair) induced soon after irradiation is optimally functional for few hours following irradiation, the metabolic perturbations caused by 2DG (including depletion of energy; ATP) appears to be efficient in enhancing the prodeath pathways and/or reducing the prosurvival pathways (including DNA repair) under these conditions. Therefore, protocols designed based on these in vitro observations will be more effective in providing local tumor control. Short-term treatment with 2DG (2-4 hours, mostly at $5 \mathrm{mM}$ concentration,equimolar with glucose in the medium) has earlier been reported to significantly increase radiation-induced micronuclei formation, or inhibit PLDR in BMG-1 and other tupes of cancer cells (Kalia and Devi, 1994; Jain et al., 1997; Kalia, 1999). Aft et al., have also showed a 50\% decrease in cell survival in cells treated for 4 hours with $4 \mathrm{mM} 2 \mathrm{DG}$ in a culturing period of 14 days compared to non-treated control cells (Aft et al., 2002). The present observation, therefore, support the above mentioned studies from the treatment time point of view. In addition, it was shown that 2DG could significantly enhanced anticancer activity of doxorubicin and decrease organ toxicity and enhance the antitumor efficacy (Cao et al., 2013). The present data, therefore, strongly suggest that further preclinical studies should be undertaken to investigate the mechanisms of action as well as potential of glycolytic inhibitorsincluding 2DG to selectively modulate the radiation response of treatment tumors, including malignant radioresistance tumors.

Our findings showed that combination of DOX/2DG/ IR have most effective potential impact in reducing the viability of SKBR3 cell line. The reduction were $58.9 \%$ without irradiation, $51.3 \%$ for $100 \mathrm{cGy}$ irradiation, $48.7 \%$ for $150 \mathrm{cGy}$, and finally 48.5 for $200 \mathrm{cGy}$ in presence of DOX/2DG. This study indicate that DOX/2DG, when combined with radiotherapy, inhibits breast cancer cell growth which may be due to either the growth arrest or the cell death. Consequently, combination of DOX/2DG and Radiation, at different doses, caused cell killing and was significantly different from either treatment alone in both cell lines (Figure 3). The result showed an additive effect of irradiation on SKBR3 cells and support that this cell line is more sensitive compared with T47D, for different doses of radiation. Therefore, the combined treatment has benefit of decreasing the treatment induced side effects from high therapeutic doses needed in chemotherapy or radiotherapy alone.

\section{Acknowledgements}

We express our gratitude to the head and all staff members of the oncology department of Imam Reza Hospital of Tabriz University of Medical Sciences for their sincere cooperation. We wish to have a special thanks to Prof. Jafar Majidi Zolbanin, head of the immunology department, and Dr. Tohid Kazemi, head of the immunology lab, for providing a proper study conditions. This study was financially supported by a research grant from the deputy of research in Tabriz University of Medical Sciences, Tabriz, Iran (\# 89/2 $-7 / 12)$.

\section{References}

Aft RL, Zhang FW, and Gius D (2002). Evaluation of 2-deoxy$\mathrm{D}$-glucose as a chemotherapeutic agent: mechanism of cell death. Br J Cancer, 87, 805-12.

Aghaee F, Pirayesh Islamian J, Baradaran B (2012). Enhanced radiosensitivity and chemosensitivity of breast cancer cells by 2-deoxy-d-glucose in combination therapy. $J$ Breast Cancer, 15, 141-7.

Aghaee F, Pirayesh Islamian J, Baradaran B, et al (2013). Enhancing the radiation induced apoptosis in T47D and SKBR3 breast cancer cells by a low dose doxorubicin treatment. J Breast Cancer, 16, 164-70.

Ahmad I, Mustafa EH, Mustafa NH, et al (2010). 2DG enhances the susceptibility of breast cancer cells to doxorubicin. Open Life Sci, 5, 739-48.

Andringa KK, Coleman MC, Aykin-Burns N, et al (2006). Inhibition of glutamate cysteine ligase (GCL) activity sensitizes human breast cancer cells to the toxicity of 2-deoxy-D- glucose. Cancer Res, 66, 1605-10.

Aykin-Burns N, Ahmad IM, Zhu Y, et al (2009). Increased levels of superoxide and $\mathrm{H}_{2} \mathrm{O}_{2}$ mediate the differential susceptibility of cancer cells versus normal cells to glucose deprivation. Biochem J, 418, 29-37.

Bergh J, Jönsson PE, Glimelius B, et al (2001). Swedish council of technology assessment in Health Care. A systematic overview of chemotherapy effects in breast cancer. Acta Oncol, 40, 253-81.

Butt AJ, Firth SM, King MA, et al (2000). Insulin-like growth factor-binding protein- 3 modulates expression of Bax and Bcl-2 and potentiates p53-independent radiation-induced apoptosis in human breast cancer cells. J BiolChem, 275, 39174-81.

Cao J, Cui S, Li S, et al (2013). Targeted cancer therapy with a 2-deoxyglucose-based adriamycin complex. Cancer Res, 73, 1362-73.

Carter SK (1979). CROS conference on combined modalities chemotherapy/radiotherapy. cancer chemother Pharmacolo, 2, 139-42.

Chabner BA, Ryan DP, Paz-Ares L, et al (2001). Antineoplastic agents. In 'The Pharmacological Basis of Therapeutics' , Eds Hardman JG, Limbird LE, Gilman AG. Goodman and Gilman's. 10 ${ }^{\text {th }}$ Ed. New York: McGraw-Hill Medical Publishing Division, 1389-99.

Coleman MC, Asbury CR, Daniels D, et al (2008). 2-DeoxyD-glucose causes cytotoxicity, oxidative stress, and radiosensitization in pancreatic cancer. Free Radic Biol Med, 44, 322-31.

Dwarakanath BS, Jain VK (1987). Modification of the radiation induced damage by 2-deoxy-D-glucose in organ cultures of human cerebral gliomas. Int J Radiat Oncol Biol Phys, 13, 741-6.

Dwarakanath BS (2009). Cytotoxicity, radiosensitization and chemosensitization of tumor cells by 2-deoxy-D-glucose in vitro. $J$ Cancer Ref Ther, 5, 27-31.

Dwarkanath BS,ZolzerF, Chandana S, et al (2001). Heterogeneity in 2-deoxy-D-glucose-induced modifications in energetics and radiation responses of human tumor cell lines. Int $J$ Radiat Oncol Biol Phys, 50, 1051-61.

Esposito F, Chirico G, Montesano Gesualdi N, et al (2003). Protein kinase $\mathrm{B}$ activation by reactive oxygen species is independent of tyrosine kinase receptor phosphorylation and requires SRC activity. $J$ Biol Chem, 278, 20828-34. 
Jalil Pirayesh Islamian et al

Ghilotti M, Pierotti MA, Gariboldi M (2010). Molecular markers for prediction of risk of radiation-related injury to normal tissue. J Nucleic Acids Investig, 1, 55-61.

Gonzalez-Angulo AM, Morales-Vasquez F, Hortobagyi GN (2007). Overview of resistance to systemic therapy in patients with breast cancer. Adv Exp Med Biol, 608, 1-22.

Gupta S, Farooque A, Adhikari JS, et al (2009). Enhancement of radiation and chemotherapeutic drug responses by 2-deoxyD-glucose in animal tumors. J Cancer Res Ther, 5, 16-20.

Heminger K, Jain V, Kadakia M, et al (2006). Altered gene expression induced by ionizing radiation and glycolytic inhibitor 2-deoxy-glucose in a human glioma cell line: Implications for radiosensitization. Cancer Biol Ther, 5, 815-23.

Hollestelle A, Elstrodt F, Nagel JH, et al (2007). Phosphatidylinositol-3- OH kinase or RAS pathway mutations in human breast cancer cell lines. Mol Cancer Res, 5, 195-201.

Hortobagyi GN (1997). Anthracyclines in the treatment of cancer:An overview. Drugs, 54, 1-7.

Jain VK, Purohit SC, Pohlit W (1977). Optimization of cancer therapy: Part I. Inhibition of repair of X-ray induced potentially lethal damage by 2-Deoxy-D-Glucose in Ehrlich ascites tumour cells. Indian J Exp Biol, 15, 711-3.

$\mathrm{Ju}$ GZ, Shen B, Sun SL, et al (2007). Effect of X-rays on expression of caspase-3 and p53 in EL-4 cells and its biological implications. Biomed Environ Sci, 20, 456-9.

Kaabinejadian S, Azizi E (2008). P53 Expression in MCF7, T47D and MDA-MB 468 breast cancer cell lines treated with adriamycin using RT-PCR and immunocytochemistry. $J$ Biol Sci, 8, 380-5.

Kalia VK, Devi NK (1994). Differential modification of radiation damage in 5-bromo-2-deoxy-uridine sensitized human glioma cells and PHA-stimulated peripheral leukocytes by 2- Deoxy-D-Glucose. Indian J Exp Biol, 32, 637-42.

Kalia VK, Prabhakara S, Narayanan V (2009). Modulation of cellular radiation responses by 2-deoxy-D-glucose and other glycolytic inhibitors: implications for cancer therapy. J Cancer Res Ther, 5, 57-60.

Kalia VK (1999). Optimizing radiation therapy of brain tumors by combination of 5-bromo-2-deoxy-uridine and 2-deoxyD-glucose. Indian J Med Res, 109, 182-7.

Kerr JF, Winterford CM, Harmon BV (1994). Apoptosis: Its significance in cancer and cancer therapy. Cancer, 73, 2013-26.

Khaitan D, Chandna S, Arya MB, et al (2006). Differential mechanisms of radiosensitization by 2-Deoxy-D-Glucose in the monolayers and multicellular spheroids of a human glioma cell line. Cancer Biol Ther, 5, 1142-51.

Lee YJ, Galoforo SS, Berns CM, et al (1998). Glucose deprivation-induced cytotoxicity and alterations in mitogenactivated protein kinase activation are mediated by oxidative stress in multidrug-resistant human breast carcinoma cells. J Biol Chem, 273, 5294-9.

Lin X, Zhang F, Bradbury CM, et al (2003). 2-Deoxy-D-Glucoseinduced Cytotoxicity and Radiosensitization in Tumor Cells Is Mediated via Disruptions in Thiol Metabolism. Cancer Res, 63, 3413-7.

Lu X, Nannenga B, Donehower LA (2005). PPM1D dephosphorylates Chk1 and p53 and abrogates cell cycle checkpoints. Genes Dev, 19, 1162-74.

Maher JC, Krishan A, Lampidis TJ (2004). Greater cell cycle inhibition and cytotoxicity induced by 2-deoxy-D-glucose in tumor cells treated under hypoxic vs aerobic conditions. Cancer Chemother Pharmacol, 53, 116-22.

Meek WD (2004). The p53 response to DNA damage. DNA Repair, 3, 1049-56.
Mohanti BK, Rath GK, Anantha N, et al (1996). Improving cancer radiotherapy with 2-deoxy-D-glucose: Phase I/II clinical trials on human cerebral gliomas. Int J Radiat Oncol Biol Phys, 35, 103-11.

Moulder S, Hortobagyi GN (2008). Advances in the treatment of breast cancer. Clin Pharmacol Ther, 83, 26-36.

Mustafa EH, Mahmoud HT, Al-Hudhud MY, et al (2015). 2-deoxy-D-Glucose synergizes with doxorubicin or L-buthionine sulfoximine to reduce adhesion and migration of breast cancer cells. Asian Pac J Cancer Prev, 16, 3213-22.

Nakamura Y (2004). Isolation of p53-target genes and their functional analysis. Cancer Sci, 95, 7-11.

O’Shaughnessy J (2003). Liposomal anthracyclines for breast cancer: Overview. Oncologist, 8, 1-2.

Pelicano H, Martin DS, Xu RH, et al (2006). Glycolysis inhibition for anticancer treatment. Oncogene, 25, 4633-46.

Sasaki A, Udaka Y, Tsunoda Y, et al (2012). Analysis of p53 and miRNA expression after irradiation of glioblastoma cell lines. Anticancer Res, 32, 4709-13.

Simons AL, Ahmad IM, Mattson DM, et al (2007). 2-Deoxy-Dglucose combined with cisplatin enhances cytotoxicity via metabolic oxidative stress in human head and neck cancer cells. Cancer Res, 67, 3364-70.

Singh G, Lakkis CL, Laucirica R, et al (1999). Regulation of prostate cancer cell division by glucose. J Cell Physiol, 180, 431-8.

Sinthupibulyakit C, Grimes KR, Domann FE, et al (2009). p53 is an important factor for the radiosensitization effect of 2-deoxy-D-glucose. Int J Oncol, 35, 609-15.

Spitz DR, Sim JE, Ridnour LA, et al (2000). Glucose deprivationinduced oxidative stress in human tumor cells. A fundamental defect in metabolism? Ann N Y Acad Sci, 899, 349-62.

Streffer C, Beuningen V, Gross E, et al (1986). Predictive assays for the therapy of rectum carcinoma. Radiother Oncol, $\mathbf{5}$, 303-10.

Tan ML, Choong PF, Dass CR (2009). Review: Doxorubicin delivery systems based on chitosan for cancer therapy. $J$ Pharm Pharmacol, 61, 131-42.

Tewey KM, Rowe TC, Yang L, et al (1984). Adriamycin induced DNA damage mediated by mammalian DNA topoisomerase II. Science, 226, 466-8.

Wang SY, Wei YH, Shieh DB, et al (2015). 2-Deoxy-d-Glucose can complement doxorubicin and sorafenib to suppress the growth of papillary thyroid carcinoma cells. PLoS One, 10, 130959.

Zhang F, Aft RL (2009). Chemosensitizing and cytotixic effect of 2-deoxy-D-glucose on breast cancer cells. J Cancer Res Ther, 5, 41-3.

Zhuang HQ, Wang J, Yuan ZY, et al (2009). The drug-resistance to gefitinib in PTEN low expression cancer cells is reversed by irradiation in vitro. J Exp Clin Cancer Res, 28, 123. 